\title{
Development of a rapid detection method for genetically modified rice using the ultra-fast PCR system
}

\author{
Min Ki Shin ${ }^{1,2}$ (D) Seon Min Jeon ${ }^{1}$ Yong Eui Koo ${ }^{1}$
}

Received: 5 May 2021/Revised: 5 October 2021 / Accepted: 15 December 2021 / Published online: 22 January 2022

(C) The Korean Society of Food Science and Technology 2022

\begin{abstract}
Genetically modified (GM) rice varieties containing traits such as tolerance to abiotic stress and resistance against pests and diseases continue to be developed. However, contamination incidents from unauthorized GM rice varieties have been encountered. To date, no GM rice crop has been authorized for consumption and/or commercialization in Korea. Therefore, to enhance safety management of unauthorized genetically modified organisms (GMOs), accurate and reliable detection methods are needed to identify GMOs in crops or products. In this study, we developed rapid detection methods for GM rice events (Bt63, KMD1, Kefeng6, Kefeng8, and LLRice62) using ultra-fast PCR system. Ultra-fast PCR is a state-ofthe-art technology and decreases PCR run-times dramatically. However, the ultra-fast PCR is not widely used in GMO analysis. Thus, we designed a detection method for five events of GM rice and confirmed them by performing specificity, sensitivity, and applicability assays. All results demonstrate that the ultra-fast PCR system is a specific, sensitive, and reliable method to identify and monitor GM rice events. Additionally, it can be utilized as a rapid and
\end{abstract}

Min Ki Shin

mkhj1212@korea.kr

Seon Min Jeon

jsm0065@korea.kr

Yong Eui Koo

kye2020@korea.kr

1 Food Safety Risk Assessment Department, National Institute of Food and Drug Safety Evaluation, Cheongju 28159, Republic of Korea

2 Interdisciplinary Program in Biological and Chemical Engineering, Seoul National University, Seoul 08826, Republic of Korea simple method for GMO analysis in crops or processed products. This study can be used as a reference for future research on new analysis methods of unauthorized GMOs.

Keywords Oryza sativa · Plasmid reference - Event specific qualification - Unauthorized GM rice

\section{Introduction}

Rice is one of the major crops cultivated in the world and is a principal food consumed by the global population. China is the largest rice producer and consumer in the world and devotes approximately $20 \%$ of its cultivated area to rice production (Chen et al., 2011). In Korea, rice production reached approximately 3.74 million tons in 2019, according to Statistics Korea.

Genetically modified (GM) rice was first developed in 1988 through electroporation or polyethylene glycol-mediated protoplast transformation methods (Fraiture et al., 2016). Since 1988, various traits such as tolerance to abiotic stresses, resistance against pests and diseases, and increased nutritional values have been introduced into rice (Bajaj and Mohanty, 2005). In 2020, according to the GM Approval Database (www.isaaa.org/gmapprovaldatabase/ default.asp) of the International Service for the Acquisition of Agri-biotech Applications (ISAAA), seven GM rice events have been developed, namely GM shanyou63, GR2E, Huahui-1/TT51-1, LLRice06, LLRice601, LLRice62, and Tarom molaii + cry1 Ab.

The transgenic rice lines Bt63 (TT51-1), Kemingdao1 (KMD1), Kefeng6, and Kefeng8 are widely known events developed in China. The Bt63 includes a hybrid CrylAb/Ac gene (an insect-resistant trait) that was granted the safety certificate by China in 2009. The KMD1 rice line is 
resistant to lepidopteran pest species (a synthetic crylAb gene) and has the potential to be approved in China. The Kefeng6 and Kefeng8 contain two insect-resistant genes, crylAc and cowpea trypsin inhibitor (CpTI) gene (Lu et al., 2016; Wang et al., 2012). The LLRice62 contains glufosinate herbicide-tolerant bar gene and phosphinothricin- $N$ acetyltransferase (PAT) proteins (Oberdoerfer et al., 2005).

Unauthorized GM rice varieties have been found in many countries. The number of GM rice contamination incidents were the highest among all other crops (Cotter and Price, 2014). Illegal cultivation of unapproved GM rice in China was reported in 2005 (Zi, 2005). In 2006, Bayer's LLRice601 and LLRice62 have been discovered across the world (Greenpeace International, 2006). Bt63 was also detected in Europe and identified in imported food products according to the Rapid Alert System for Food and Feed (RASFF) (Lu et al., 2016; Price and Cotter, 2014). For these reasons, accurate and reliable detection methods are needed for the identification and analysis of unauthorized GMOs crops or products.

Numerous studies have been conducted to identify detection methods for GM rice. Detection methods for GM Bt63 have been developed using real-time PCR (Grohmann and Mäde, 2009; Wu et al., 2010) and droplet digital PCR (Wang et al., 2019). Furthermore, the qualitative and quantitative assays for KMD1, Kefeng6, LLRice62 and LLRice601 analysis have been previously established (Babekova et al., 2009; Guertler et al., 2012; Wang et al., 2011; Watanabe et al., 2007). The aim of most studies investigating screening assays for GM rice explored simple and cost-effective methods to identify GMOs (Safaei et al., 2019; Zang et al., 2015). Recently, the detection methods for other various GM rice such as M12 and G6H1 have been developed (Deng et al., 2020; Xu et al., 2019). Conventional PCR and real-time PCR are the classical and most widely accepted GMO detection methods.

Time and cost are important factors in the analysis. The use of the ultra-fast PCR system can decrease the PCR run time dramatically. Also, the amount of reagent used for analysis can be reduced. For this reason, the ultra-fast PCR system has recently been studied and utilized in various fields. The recent examples of the ultra-fast PCR system are COVID-19 causative virus detection, tuberculosis diagnosis, and the authenticity determination of food raw materials.

While the ultra-fast PCR system based on Rapi:chip ${ }^{\mathrm{TM}}$ is a state-of-the-art technology, not enough research has been conducted using this method in order to establish assay for GMO detection. Therefore, this study aimed to develop a simple, rapid, and effective detection method for five GM rice events (Bt63, KMD1, Kefeng6, Kefeng8, and LLRice62).

\section{Materials and methods}

\section{Standard plasmid and reference materials}

The standard plasmid (pUC-RICE5) used in this study was developed through research conducted by the Ministry of Food and Drug Safety (MFDS) in Korea. Owing to a limited access to unauthorized GM rice Certified Reference Materials (CRMs), plasmid DNA was used for positive reference of PCR assays. The plasmid that was cloned into a pUC19 vector with ampicillin resistance contained the endogenous sucrose phosphate synthase (SPS) gene and five GM rice events (Bt63, KMD1, Kefeng6, Kefeng8, and LLRice62) sequences (Fig. 1).

Reference materials of GM soybean (RRS, MON89788, A2704-12, DP-356043-5, DP-305423-1, A5547-127, MON87701, CV127, MON87769, MON87705, MON87708, FG72, SYHT0H2, DAS-44406-6, DAS68416-4, DAS-81419-2, and MON87751) and maize (MON810, GA21, TC1507, NK603, MON863, Bt11, T25, Bt176, DLL25, DAS-59122-7, MON88017, MIR604, Bt10, MON89034, MIR162, DP-098140-6, 3272, MON87460, 5307, MON87427, DAS-40278-9, DP004114-3, MON87411, VCO-01981-5, MON87403, and MON87419) were kindly provided by the developers (Table 1). Non-GM (NGM) seeds of soybean, maize, canola, rice, wheat, potato, and barley were also used in this study.

\section{DNA extraction}

NGM crops, GM soybean, and maize seeds and processed products were separately milled with a grinder. GM soybean mix (17 events) and maize mix (26 events) samples were produced by mixing $0.1 \mathrm{~g}$ of ground powder from each event. Genomic DNA was extracted from the powder samples using a PowerPrep ${ }^{\mathrm{TM}}$ DNA Extraction from Food and Feed kit (Kogenebiotech, Korea) according to the manufacturer's instructions.

DNA concentrations were determined by QUBIT ${ }^{\mathrm{TM}} 3.0$ Quantitation Kit (Thermo Fisher Scientific, Wilmington, DE, USA). DNA samples were diluted in nuclease-free water to a final concentration of $10 \mathrm{ng} / \mu \mathrm{L}$ and stored at $-20{ }^{\circ} \mathrm{C}$.

\section{Primers}

The event-specific primers of the five GM rice events were used in the ultra-fast PCR assays. The SPS gene was used as the endogenous reference gene. OsSPS-F/R primer sets were previously shown to detect the SPS gene (Kim et al., 2010). The Bt63-KF/KR, KMD1-KFr/KRr, Kef6-KF/KR, 
Fig. 1 Schematic diagram of pUC-RICE5 plasmid which contained the endogenous sucrose phosphate synthase (SPS) gene and five GM rice events (Bt63, KMD1, Kefeng6, Kefeng8, and LLRice62) sequences with restriction site of XhoI, SacII and BglII were cloned into a pUC57 vector with the ampicillin resistance

Table 1 Reference materials used in this study

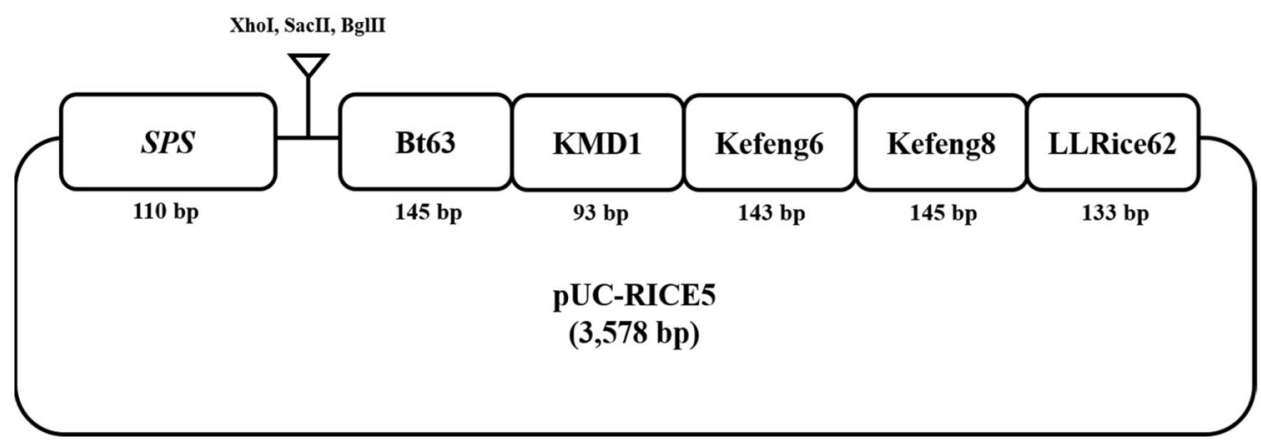

\begin{tabular}{llllll}
\hline Crop & Event Name & Developer & Crop & Event Name & Developer \\
\hline Soybean & RRS & Monsanto & Maize & Bt11 & Syngenta \\
Soybean & MON89788 & Monsanto & Maize & T25 & Bayer CropScience \\
Soybean & A2704-12 & Bayer CropScience & Maize & Bt176 & Syngenta \\
Soybean & DP-356043-5 & Pioneer & Maize & DLL25 & Monsanto \\
Soybean & DP-305423-1 & Pioneer & Maize & DAS-59122-7 & Dow AgroScience \\
Soybean & A5547-127 & Bayer CropScience & Maize & MON88017 & Monsanto \\
Soybean & MON87701 & Monsanto & Maize & MIR604 & Syngenta \\
Soybean & CV127 & BASF plant Science & Maize & Bt10 & Syngenta \\
Soybean & MON87769 & Monsanto & Maize & MON89034 & Monsanto \\
Soybean & MON87705 & Monsanto & Maize & MIR162 & Syngenta \\
Soybean & MON87708 & Monsanto & Maize & DP-098140-6 & Pioneer \\
Soybean & FG72 & Bayer CropScience & Maize & 3272 & Syngenta \\
Soybean & SYHT0H2 & Syngenta & Maize & MON87460 & Monsanto \\
Soybean & DAS-44406-6 & Dow AgroScience & Maize & 5307 & Syngenta \\
Soybean & DAS-68416-4 & Dow AgroScience & Maize & MON87427 & Monsanto \\
Soybean & DAS-81419-2 & Dow AgroScience & Maize & DAS-40278-9 & Dow AgroScience \\
Soybean & MON87751 & Monsanto & Maize & DP-004114-3 & Pioneer \\
Maize & MON810 & Monsanto & Maize & MON87411 & Monsanto \\
Maize & GA21 & Syngenta & Maize & VCO-01981-5 & Genective \\
Maize & TC1507 & Pioneer & Maize & MON87403 & Monsanto \\
Maize & NK603 & Monsanto & Maize & MON87419 & Monsanto \\
Maize & MON863 & Monsanto & & & \\
\hline & & & &
\end{tabular}

Kef8-KF/KR, and LLR62-KF/KR primer pairs were based on the $3^{\prime}$ integration flanking sequence between the T-DNA and the host rice genome of GM rice EU880444 (Bt63), EU980363 (KMD1), HQ161057 (Kefeng6), HQ161059 (Kefeng8), and JQ406881 (LLRice62), respectively (Kim et al., 2017). The primers were synthesized by Bioneer (Daejeon, Korea) and the oligonucleotide sequences have been listed in Table 2 .

\section{Ultra-fast PCR system}

The ultra-fast PCR analyzes on the same principle as SYBR green based real-time PCR, except that Evagreen dye is used instead of SYBR green as an intercalating dye.
The PCR analysis was performed on the GENECHECKER UF-150 Ultra-fast Real-Time qPCR system (Genesystem, Daejeon, Korea) with Rapi:chip ${ }^{\mathrm{TM}}$. For the final reaction volume $10 \mu \mathrm{L}, 5 \mu \mathrm{L}$ of SSO Fast ${ }^{\mathrm{TM}}$ EvaGreen Supermixes (Bio-Rad Laboratories, Berkeley, CA, USA), $1 \mu \mathrm{L}$ of each forward and reverse primer $(0.8 \mu \mathrm{M})$, and $2 \mu \mathrm{L}$ of the DNA template were used. All ultra-fast PCR assays were performed under the following conditions: 1 cycle of initial denaturation at $95{ }^{\circ} \mathrm{C}$ for $1 \mathrm{~min} ; 40$ cycles of denaturation at $95{ }^{\circ} \mathrm{C}$ for $5 \mathrm{~s}$; annealing at $58{ }^{\circ} \mathrm{C}$ for $5 \mathrm{~s}$; extension at $72{ }^{\circ} \mathrm{C}$ for $5 \mathrm{~s} ; 1$ cycle of elongation at $72{ }^{\circ} \mathrm{C}$ for $5 \mathrm{~s}$. No template control (NTC) was used as the negative control in the ultra-fast PCR reaction. 
Table 2 Oligonucleotide primers used in this study

\begin{tabular}{|c|c|c|c|c|}
\hline Target & Name & Sequence $\left(5^{\prime} \rightarrow 3^{\prime}\right)$ & Length (bp) & GeneBank accession no. \\
\hline \multirow[t]{2}{*}{ SPS } & OsSPS-F & GAT CGG TTC CGC CAT TAG CA & 110 & U33175 \\
\hline & OsSPS-R & AAC CGA GCG CGA TCA CTT GC & & \\
\hline \multirow[t]{2}{*}{ Bt63 } & Bt63-KF & CGC GCC ACA TAG CAG AAC TT & 145 & EU880444 \\
\hline & Bt63-KR & CAC TCG TCC GGG ATC CTC TA & & \\
\hline \multirow[t]{2}{*}{ KMD1 } & KMD1-KFr & CAT TAA AAA CGT CCG CAA TGT G & 93 & EU980363 \\
\hline & KMD1-KRr & TAC GCC GAT ATG CCT GCC CA & & \\
\hline \multirow[t]{2}{*}{ Kefeng6 } & Kef6-KF & GAG GCC ATG ATC TGG TGT CC & 143 & HQ161057 \\
\hline & Kef6-KR & TTG CGG TGG AAC ACC GAA GC & & \\
\hline \multirow[t]{2}{*}{ Kefeng8 } & Kef8-KF & GCC GGT CTT GCG ATG ATT AT & 145 & HQ161059 \\
\hline & Kef8-KR & GAC CAT GAT GCT GTT CTG CC & & \\
\hline \multirow[t]{2}{*}{ LLRice62 } & LLR62-KF & AAC ACG CAC ACT CAC CTA CT & 133 & JQ406881 \\
\hline & LLR62-KR & CAG CTG GCG TAA TAG CGA AG & & \\
\hline
\end{tabular}

\section{Specificity, sensitivity, and application test}

The specificity of the designed detection method was evaluated using various crops and GM events. A sensitivity test was conducted to identify detectable concentration for each target event. We compared the sensitivity results of genomic DNA and plasmid using endogenous gene (SPS) primers. Additionally, the designed method was used in commercial rice containing foods to investigate its applicability in processed products.

To confirm the specificity and sensitivity of the ultra-fast PCR detection method for five GM rice events, plasmid DNA samples were prepared. The copy number of the pUC-RICE5 plasmid was calculated using Formula (1) mentioned below:

$\mathrm{m}=[\mathrm{n}]\left[1.096 \times 10^{-21} \mathrm{~g} /\right.$ copy $]$

where $\mathrm{m}$ is mass and $\mathrm{n}$ is the recombinant plasmid or genome size (bp).

For the sensitivity analysis, plasmid DNA was serially diluted 10 times in TE buffer $(10 \mathrm{mM}$ Tris- $\mathrm{HCl}, \mathrm{pH} 8.0$; $1 \mathrm{mM}$ EDTA) to four concentrations ranging from $2 \times 10^{4}$ to $2 \times 10^{1}$ copies per reaction. The genomic DNA concentrations of NGM rice was ranged from 2 to 0.002 ng per reaction and the dilution was performed in nuclease-free water.

\section{Results and discussion}

\section{Specificity}

To evaluate the specificity of the ultra-fast PCR detection method, the assays involving all primers were performed using genomic DNA templates of NGM crops (seven crops; soybean, maize, canola, rice, wheat, potato, and barley), GM soybean (mix of seventeen events), and GM maize (mix of twenty-six events). The results showed a single peak detected from each target GM rice event, and there were no specific amplifications for non-target crops, events, and NTC (Fig. 2). Additionally, the melting temperature $(\mathrm{Tm})$ of the amplification products obtained from each target was $85.60{ }^{\circ} \mathrm{C}, 78.47{ }^{\circ} \mathrm{C}, 83.01{ }^{\circ} \mathrm{C}, 76.85{ }^{\circ} \mathrm{C}$, and $80.09{ }^{\circ} \mathrm{C}$ for Bt63, KMD1, Kefeng6, Kefeng8, and LLRice62, respectively (Table 2). Five GM rice events can be selectively distinguished from each other by $\mathrm{Tm}\left({ }^{\circ} \mathrm{C}\right)$ values since the amplicons have specific $\mathrm{Tm}$ values.

Consequently, these results showed that the detection methods established in this study had high specificity for the target primer sets. This method can be utilized to identify and monitor GM rice events, and rapid analysis results can be obtained in approximately $20 \mathrm{~min}$.

\section{Sensitivity}

Unauthorized GMOs encounter zero-tolerance or low-percentage tolerance policies in many countries (Fraiture et al., 2017). Therefore, the development of a sensitive detection method is necessary for the identification of the presence of unapproved GMOs. To assess the sensitivity of the ultra-fast PCR method, pUC-RICE5 plasmid was serially diluted 10 times to concentrations ranging from 20,000 to 20 copies per reaction. The $\mathrm{Ct}$ and $\mathrm{Tm}$ values of the amplification results for each event were analyzed.

For all GM rice events, primer sets for 20 copies of target DNA were sufficient for their identification. Based on the copy number of rice (One copy number for haploid genome of rice (Oryza sativa) is considered $0.47 \mathrm{pg}$ 

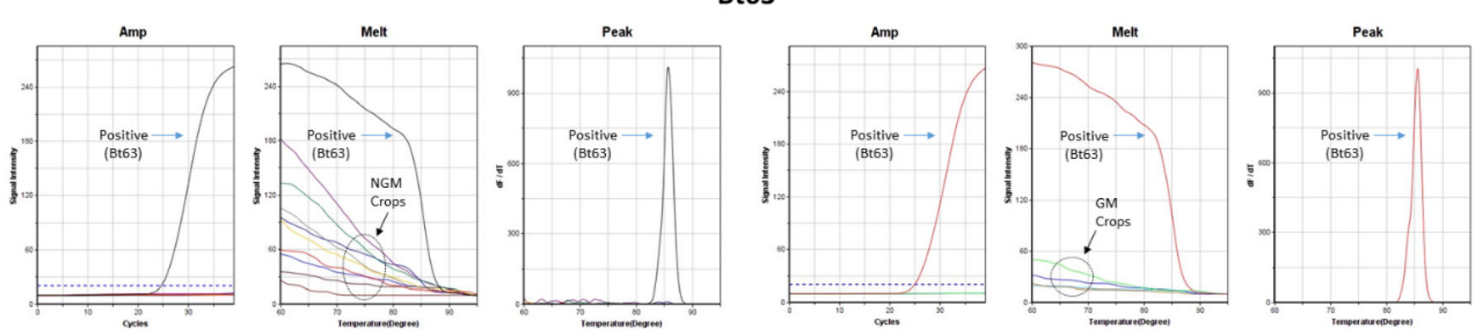

(A)

KMD1
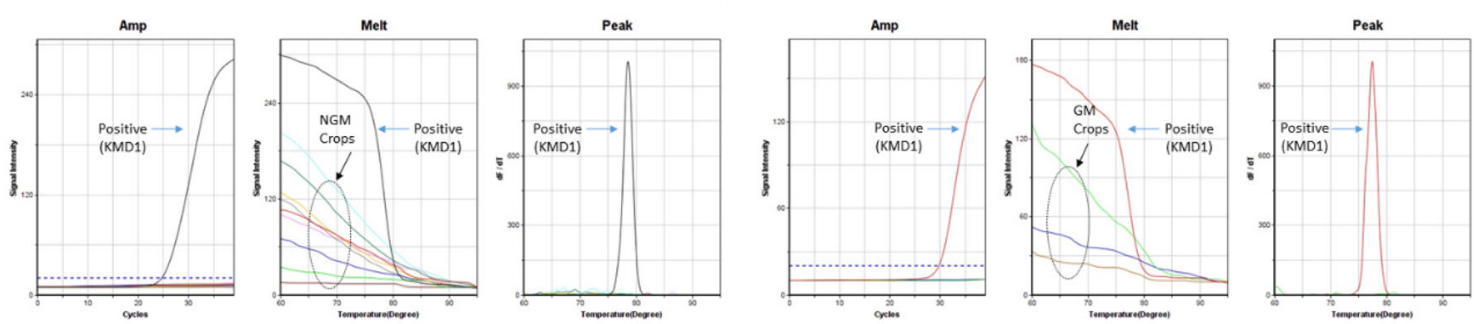

(C)

(D)
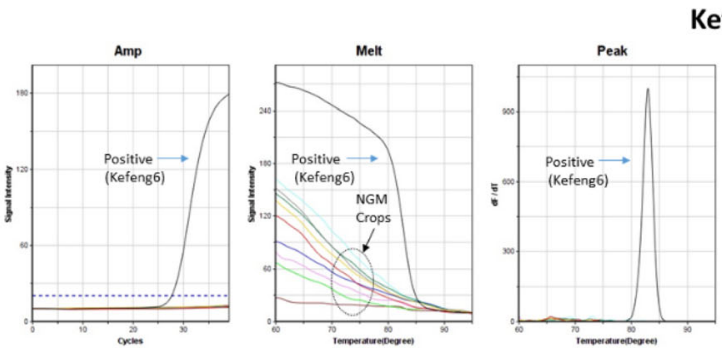

Kefeng6

(E)
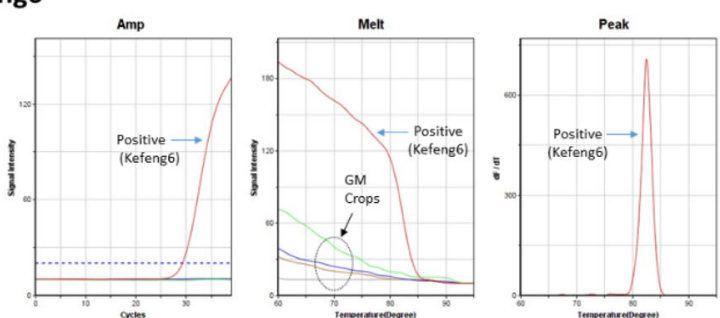

(F)

Kefeng8
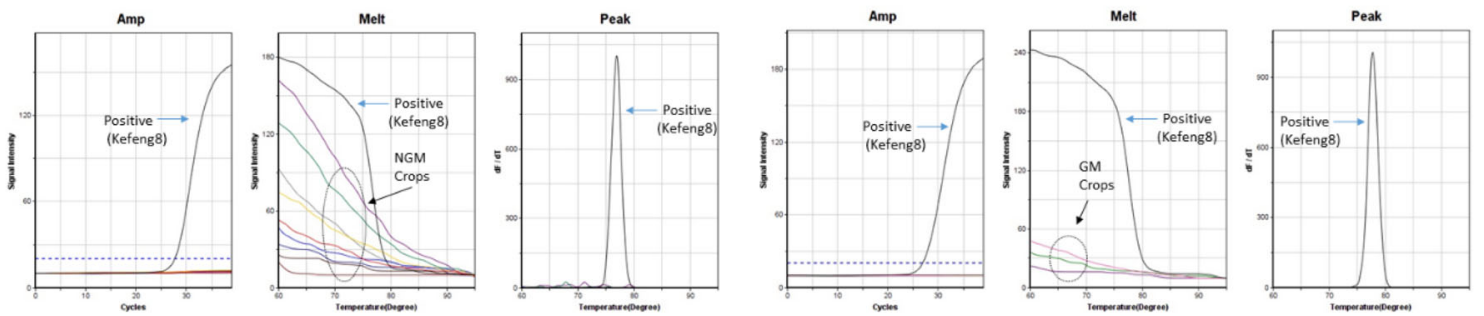

(G)

LLRice62

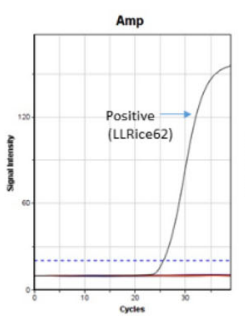

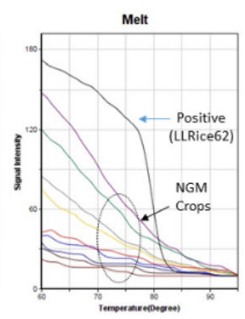

(I)

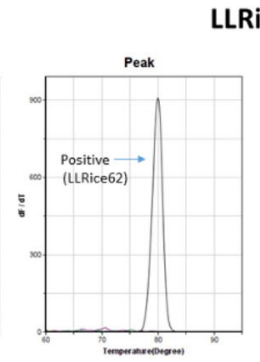

ents using Ultra-fast Fig. 2 Primer specificity for five GM rice events using Ultra-fast
PCR. (A, C, E, G, I) Specificity results for Non-GM crops (seven crops; soybean, maize, canola, rice, wheat, potato, and barley) DNA;

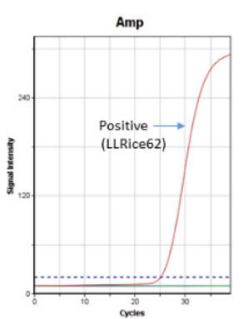

(B, D, F, H, J) Specificity results for GM soybean (mix of seventeen events) and GM maize (mix of twenty-six events) DNA 
(Arumuganathan and Earle, 1991)), 20 copies can be calculated to approximately $0.009 \mathrm{ng}$.

To test the sensitivity for genomic DNA, extracted from NGM rice was used due to the limited access to unapproved GM rice varieties. The PCR assays were performed using SPS primer pairs and the results were compared to the results obtained from plasmid DNA. The results indicated that genomic and plasmid DNA were detected in $0.002 \mathrm{ng}$ and 20 copies, respectively (Table 3 ).

These results demonstrated that rapid detection method used in this study was highly sensitive and accurate. Furthermore, we confirmed that these assays were applicable for genomic DNA templates and compared its sensitivity to the sensitivity for plasmid DNA. While the Tm value of Bt63 $\left(85.68{ }^{\circ} \mathrm{C}\right)$ was similar to the Tm value obtained for the SPS primer set, the specificity results showed no NGM rice detection for these primer sets.

Table 3 Sensitivity results of the Ultra-fast PCR method

\begin{tabular}{|c|c|c|c|c|c|}
\hline \multirow[t]{2}{*}{ Events } & \multirow[t]{2}{*}{ Conc. } & \multicolumn{2}{|c|}{$\mathrm{Ct}$ value } & \multicolumn{2}{|c|}{$\operatorname{Tm}\left({ }^{\circ} \mathrm{C}\right)$ value } \\
\hline & & Mean & $\mathrm{SD}$ & Mean & $\mathrm{SD}$ \\
\hline \multirow[t]{4}{*}{ SPS } & 20,000 copies & 25.12 & 0.44 & 85.08 & 0.24 \\
\hline & 2000 copies & 28.43 & 0.01 & & \\
\hline & 200 copies & 32.38 & 1.29 & & \\
\hline & 20 copies & 34.82 & 0.70 & & \\
\hline \multirow[t]{4}{*}{ Bt63 } & 20,000 copies & 23.98 & 0.62 & 85.68 & 0.41 \\
\hline & 2,000 copies & 27.84 & 0.62 & & \\
\hline & 200 copies & 31.29 & 0.03 & & \\
\hline & 20 copies & 35.23 & 0.04 & & \\
\hline \multirow[t]{4}{*}{ KMD1 } & 20,000 copies & 25.10 & 0.02 & 78.03 & 0.34 \\
\hline & 2000 copies & 29.58 & 0.68 & & \\
\hline & 200 copies & 32.59 & 0.69 & & \\
\hline & 20 copies & 36.69 & 0.84 & & \\
\hline \multirow[t]{4}{*}{ Kefeng6 } & 20,000 copies & 26.75 & 0.54 & 83.37 & 0.32 \\
\hline & 2000 copies & 32.15 & 1.41 & & \\
\hline & 200 copies & 33.70 & 0.64 & & \\
\hline & 20 copies & 36.25 & 1.44 & & \\
\hline \multirow[t]{4}{*}{ Kefeng8 } & 20,000 copies & 25.73 & 0.64 & 77.70 & 0.38 \\
\hline & 2000 copies & 29.66 & 0.63 & & \\
\hline & 200 copies & 33.15 & 0.01 & & \\
\hline & 20 copies & 35.69 & 2.09 & & \\
\hline \multirow[t]{4}{*}{ LLRice62 } & 20,000 copies & 26.41 & 0.01 & 80.05 & 0.36 \\
\hline & 2000 copies & 29.40 & 0.01 & & \\
\hline & 200 copies & 33.68 & 0.64 & & \\
\hline & 20 copies & 35.73 & 0.76 & & \\
\hline SPS & $2 \mathrm{ng}$ & 24.97 & 0.04 & 85.16 & 0.24 \\
\hline \multirow[t]{3}{*}{ (gDNA) } & $0.2 \mathrm{ng}$ & 26.53 & 0.71 & & \\
\hline & $0.02 \mathrm{ng}$ & 31.96 & 0.01 & & \\
\hline & $0.002 \mathrm{ng}$ & 33.92 & 0.01 & & \\
\hline
\end{tabular}

$S D$ standard deviation

\section{Application of ultra-fast PCR in commercial processed products}

To evaluate the application of ultra-fast PCR assays, a total of thirteen commercially available rice processed products were selected. The selected products included noodles, cookies, ready-made meals, and other items. Genomic DNA extracted from processed products was used as DNA template for the ultra-fast PCR analysis. The applicability of this method for commercially available products is shown in Table 4. For all products, the SPS primers led to amplification and a $\mathrm{Tm}$ value of approximately $84.5^{\circ} \mathrm{C}$ was observed. The primer sets for GM Bt63, KMD1, Kefeng6, Kefeng8, and LLRice62 events did not lead to amplicon production in any of the products. We confirmed that the rice from the processed products used in this study did not contain any of the above-mentioned five GM events. One of the main limitations of this study is represented by the lack of available products containing unauthorized GM rice. However, the ultra-fast PCR system used in this study has potential applications in the analysis of processed products based on the results of amplification of endogenous SPS gene in rice.

A rapid detection method for five GM rice events using the ultra-fast PCR system with Rapi:chip ${ }^{\mathrm{TM}}$ was designed to selectively detect target primer sets that amplified at a specific melting temperature. Furthermore, this method was sensitive enough to detect a low concentration of GM rice DNA. Moreover, the wide applicability of the ultrafast PCR method was demonstrated by its capacity to detect and monitor rice DNA in processed products. Thus, it can be utilized as a rapid and simple method for GMO analysis as it only used the event-specific primer sets without the need for a specific probe. The ultra-fast PCR assay established in this study is a specific, sensitive, and reliable method for GM rice event identification, which delivers the results within approximately $20 \mathrm{~min}$.

Compared to the existing detection methods, the ultrafast PCR method is an economical and eco-friendly method that uses a smaller amount of reagents. Also, the inspection takes a very short time, comparatively, it is $18 \%$ of the conventional PCR inspection time and $23 \%$ of the real-time PCR. There is an advantage in that the test results can be confirmed in a short time due to short duration between cycles and high thermal conductivity of the device. In addition, it is possible to apply the test not only in a laboratory but also in the field, as a portable type small analyzer is able to be supported. In conclusion, we developed a rapid and sensitive PCR method for five non-approved GM rice events, Bt63, KMD1, Kefeng6, Kefeng8, and LLRice62, which are under strict safety management. The ultra-fast PCR system has an economic advantage by using half the reaction reagent compared to the current PCR 
Table 4 Ultra-fast PCR results for rice DNA in processed products

\begin{tabular}{|c|c|c|c|c|c|c|}
\hline \multirow[t]{2}{*}{ Products } & \multicolumn{6}{|c|}{$\mathrm{Tm}\left({ }^{\circ} \mathrm{C}\right)$ value } \\
\hline & SPS & Bt63 & KMD1 & Kefeng6 & Kefeng8 & LLRice62 \\
\hline PHO BO XUA \& NAY BEEF FLAVOUR & $+(84.95)$ & ND & ND & ND & ND & ND \\
\hline JIA YUAN SNACK(CUMIN) & $+(84.31)$ & ND & ND & ND & ND & ND \\
\hline NON GLUTINOUS BROWN RICE & $+(84.31)$ & ND & ND & ND & ND & ND \\
\hline PHO GA XUA \& NAY CHICKEN FLAVOUR & $+(84.95)$ & ND & ND & ND & ND & ND \\
\hline HU TIEU NAM VANG & $+(84.95)$ & ND & ND & ND & ND & ND \\
\hline RICE STICK & $+(83.63)$ & ND & ND & ND & ND & ND \\
\hline BANH DA CUA & $+(83.98)$ & ND & ND & ND & ND & ND \\
\hline UNRIPED PEPPER PREPARATION & $+(83.98)$ & ND & ND & ND & ND & ND \\
\hline HOT KID BABY MUM-MUM RICE RUSK VEGETABLE & $+(84.63)$ & ND & ND & ND & ND & ND \\
\hline GLUTINOUS RICE BALLS WITH BLACK SESAME FILLING & $+(84.95)$ & ND & ND & ND & ND & ND \\
\hline INJEOLMI COOKIE & $+(84.31)$ & ND & ND & ND & ND & ND \\
\hline PAD THAI STIR-FRY NOODLE MEAL & $+(84.63)$ & ND & ND & ND & ND & ND \\
\hline KRA YA SART CRISPY RICE COOKIE & $+(84.95)$ & ND & ND & ND & ND & ND \\
\hline
\end{tabular}

$N D$ not determined

method, and the reaction time is also very short, by about one fourth to one fifth of the existing methods, and the analysis equipment is portable so that analysis can be done in the field. Therefore, these advantages are expanding the scope of application.

Acknowledgements We thank the research team of Professor HaeYoung Kim of Kyung Hee University for providing the standard plasmid (pUC-RICE5) used in the research.

Funding This research was supported by Grant (17161MFDS051) from the Ministry of Food and Drug Safety in Korea.

\section{Declarations}

Conflict of interest The authors declare no conflict of interest.

\section{References}

Arumuganathan K, Earle ED. Nuclear DNA content of some important plant species. Plant Molecular Biology Reporter. 9: 208-218 (1991)

Babekova R, Funk T, Pecoraro S, Engel KH, Busch U. Development of an event-specific real-time PCR detection method for the transgenic $\mathrm{Bt}$ rice linekmd1. European Food Research and Technology. 228: 707-716 (2009)

Bajaj S, Mohanty A. Recent advances in rice biotechnology-towards genetically superior transgenic rice. Plant Biotechnology Journal. 3: 275-307 (2005)

Chen M, Shelton A, Ye GY. Insect-resistant genetically modified rice in china: from research to commercialization. Annual Review of Entomology. 56: 81-101 (2011)

Deng $\mathrm{T}$, Huang $\mathrm{W}$, Xing R, Zhang J, Ren J, Ge Y, Chen Y. Establishment and application of a loop-mediated isothermal amplification method with double-stranded displacement probes to quantify the genetically modified rice M12 event. European Food Research and Technology. 246: 631-641 (2020)

Fraiture MA, Roosens NHC, Taverniers I, Loose MD, Deforce D, Herman P. Biotech rice: current developments and future detection challenges in food and feed chain. Trends Food Science Technology. 52: 66-79 (2016)

Fraiture MA, Herman P, De Loose M, Debode F, Roosens NH. How can we better detect unauthorized GMOs in food and feed chains? Trends in Biotechnology. 35: 508-517 (2017)

GM Contamination Register. Annual review of cases of contamination, illegal planting and negative side effects of genetically modified organisms - Greenpeace International, Amsterdam, The Netherlands. http://www.genewatch.org/uploads/ f03c6d66a9b354535738483c1c3d49e4/gm_contamination_ report_2006.pdf

Grohmann L, Mäde D. Detection of genetically modified rice: collaborative validation study of a construct-specific real-time PCR method for detection of transgenic Bt rice. European Food Research and Technology. 228: 497-500 (2009)

Guertler P, Huber I, Pecoraro S, Busch U. Development of an eventspecific detection method for genetically modified rice Kefeng 6 by quantitative real-time PCR. Journal fur Verbraucherschutz und Lebensmittelsicherheit. 7: 63-70 (2012)

Kim HY, Kim JH, Oh MH. Regulation and detection methods for genetically modified foods in Korea. Pure and Applied Chemistry. 82: 129-137 (2010)

Kim JH, Park SB, Roh HJ, Shin MK, Moon GI, Hong JH, Kim HY. Event-specific qualitative and quantitative detection of five genetically modified rice events using a single standard reference molecule. Food Chemistry. 226: 187-192 (2017)

Lu J, Ji GZ, Li G, Wu YF, Yang J, Lin SL, Yang DL, Zhao JN, Xiu WM. Development of a multiplex event-specific PCR assay for detection of genetically modified rice. Cereal Research Communications. 44: 47-56 (2016)

Oberdoerfer RB, Shillito RD, de Beuckeleer M, Mitten DH. Rice (Oryza sativa L.) containing the bar gene is compositionally equivalent to the nontransgenic counterpart. Journal of Agricultural and Food Chemistry. 53: 1457-1465 (2005) 
Price B, Cotter J. The GM contamination register: a review of recorded contamination incidents associated with genetically modified organisms (GMOs), 1997-2013. International Journal of Food Contamination. 1: 5 (2014)

Safaei P, Aghaee EM, Khaniki GJ, Afshari SAK, Rezaie S. A simple and accurate PCR method for detection of genetically modified rice. Journal of Environmental Health Science and Engineering. 17: 847-851 (2019)

Wang WX, Zhu TH, Lai FX, Fu Q. Event-specific qualitative and quantitative detection of transgenic rice Kefeng- 6 by characterization of the transgene flanking sequence. European Food Research and Technology. 232: 297-305 (2011)

Wang WX, Zhu TH, Lai FX, Fu Q. Event-specific qualitative and quantitative detection of transgenic rice Kefeng- 8 by characterization of the transgene flanking sequence. European Food Research and Technology. 234: 477-484 (2012)

Wang X, Tang T, Miao Q, Xie S, Chen X, Tang J, Peng C, Xu X, Wei $\mathrm{W}$, You Z, Xu J. Detection of transgenic rice line TT51-1 in processed foods using conventional PCR, real-time PCR, and droplet digital PCR. Food Control. 98: 380-388 (2019)

Watanabe T, Shiramasa Y, Furui S, Kitta K, Minegishi Y, Akiyama H, Maitani T. Development and evaluation of qualitative detection methods for unapproved genetically modified rice (LLRice). Journal of the Food Hygienic Society of Japan (Shokuhin Eiseigaku Zasshi). 48: 170-178 (2007)

Wu G, Wu Y, Nie S, Zhang L, Xiao L, Cao Y, Lu C. Real-time PCR method for detection of the transgenic rice event TT51-1. Food Chemistry. 119: 417-422 (2010)

Xu X, Chen X, Lai Y, Zhang Q, Wu Y, Li J, Wang X, Miao Q, Liu H, $\mathrm{Xu}$ J. Event-specific qualitative and quantitative detection of genetically modified rice G6H1. Food Analytical Methods. 12: 440-447 (2019)

Zhang F, Wang L, Wang R, Ying Y, Wu J. Simple screening strategy with only water bath needed for the identification of insectresistant genetically modified rice. Analytical Chemistry. 87: 1523-1526 (2015)

$\mathrm{Zi} \mathrm{X.} \mathrm{GM} \mathrm{rice} \mathrm{forges} \mathrm{ahead} \mathrm{in} \mathrm{China} \mathrm{amid} \mathrm{concerns} \mathrm{over} \mathrm{illegal}$ planting. Nature Biotechnology. 23: 637 (2005)

Publisher's Note Springer Nature remains neutral with regard to jurisdictional claims in published maps and institutional affiliations. 